\title{
Pharmacological Screening of Anti Lice and Antidandruff Activity of Ethanolic Extract of Leaves of Datura metel
}

\author{
Sreedhar V'*, J Mastanaiah', B Chakrapani', D Venkata Narayana', B Nagendra Babu', M Sushma', C Usha \\ Sree ${ }^{1}$, N Krishna Sree ${ }^{1}$
}

\section{Sreedhar V $^{1, *}$, J Mastanaiah ${ }^{1}$, B Chakrapani', D Venkata Narayana', B Nagendra Babu', M Sushma', C Usha Sree', N Krishna Sree ${ }^{1}$}

'Department of Pharmacognosy, Balaji College of Pharmacy, Rudrampeta, Alamur, Ananthapuramu, Andhra Pradesh 515001, INDIA.

\section{Correspondence}

\section{Dr. V. Sreedhar}

Professor and Principal, Balaji College of Pharmacy, Rudrampeta, Alamur Ananthapuramu, Andhra Pradesh 515001, INDIA

Tel. 9441190175

E-mail: veerabommasree@gmail. comHistory

- Submission Date: 19-06-2020;

- Review completed: 29-07-2020;

- Accepted Date: 08-08-2020

DOI : 10.5530/pj.2020.12.225

Article Available online

http://www.phcogj.com/v12/i6s

Copyright

(C) 2020 Phcogj.Com. This is an openaccess article distributed under the terms of the Creative Commons Attribution 4.0 International license.

\begin{abstract}
It should be noticed that there is no drugs is available to treat lice and dandruff both are very great public health concern. So it is necessary to screen a drug especially of herbal origin to treat the both head lice and dandruff without affecting eyes. In the present study, Datura metel leaf extracts was evaluated for their insecticidal properties using head lice as an insect model. The study was conducted from November 2019 to March 2020. Plant sample (leaf) of Datura mete/ was collected from anantapur, Andhra Pradesh, India in November 2019. The various concentration of ethanolic extract of leaves of Datura metel was prepared by using distilled water. $20 \%, 40 \%, 60 \%$ were used. A colony of P.humanus capitis was collected by combing the hair of 20-25 infected children at the age group of 10-15. Head lice were reared in the glass vessels covered with nylon mesh containing tufts of hairs. The hair tufts was impregnated with appropriate doses for the screening. Pure culture of M.furfur (MTCC: 1374) was obtained from institute of Microbial type of culture collection, Chandigarh, India. The culture was maintained in SDA medium. The current study afford scientific basis for the ethnomedical use of this plant as antilice application. It is concluded that it can be optimistic that the present work proved Datura metel of dual therapeutic advantage to be a potential phytochemical target in the design of a drug for the treatment of both lice and dandruff.

Key words: Anti dandruff, Anti lice, Datura metel, Ethnomedical use, Pharmacological Screening.
\end{abstract}

\section{INTRODUCTION}

Nearly $50 \%$ drugs used in medicine are of plant origin. ${ }^{1}$ It is desirable to have a "need based" approach to research on medicinal plants including screening of plants for biological activity. Research interest for many infections \& infestations are not much focused by researcher. One among those conditions is for head lice infestation and the fungal infection dandruff etc. Lice Infestation are common, found worldwide and affect between 6 to 20 Million people every year it is very common and mainly affect children $3 \& 12$ years. $^{2}$ The treatment of head lice is now complicated by the emergence of resistance to pediculicides. ${ }^{3}$ The management of human head lice worldwide depends primarily on the continued applications of carbamate, pyrethrin, pyrethroid, organochlorine, organophosphorus, and avermectin, insecticides. Their repeated use has often resulted in the development of resistance and increasing levels of resistance to the most commonly used pediculicides have caused multiple and excessive treatments, fostering serious human health concerns. These problems have highlighted the need for the development of selective p.humanus capitis control alternatives. ${ }^{4}$

Dandruff is a major cosmetic problem that posseses very great public health concern both in developed and developing countries. Pityrosporum ovale, a yeast like lipophilic basidiomycetous fungus is considered to be the chief cause of the problem. Presently accessible treatment options for the management of dandruff include therapeutic use of zinc pyrithione, salicylic acid immidazole derivatives, glycolic acid. ${ }^{5}$

However, these agents have certain limitations either due to poor clinical efficacy or due to compliance issues. Furthermore, these drugs are unable to prevent recurrence which is the commonest problem. It should be noticed that there is no drugs is available to treat lice and dandruff both are very great public health concern. ${ }^{6}$ Moreover the drugs used may affects the eyes during their application. So, it is necessary to screen a drug especially of herbal origin to treat the both head lice and dandruff without affecting eyes. As per available literature, Annona squamosa, Datura metel have been reported to have insecticidal properties and their efficacy has been reported against different insect models. ${ }^{7}$ In the present study, Datura metel leaf extracts was evaluated for their insecticidal properties using head lice as an insect model.

\section{MATERIALS AND METHODS}

\section{Plant extracts}

The study was conducted from November 2019 to March 2020. Plant sample (leaf) of Datura metel was collected from anantapur, Andhra Pradesh, India in November 2019. Herbaria of these plants were authenticated from Department of Botany, Sri Krishnadevaraya University, Anantapur and 
authentication numbers of the herbaria for Datura metel Linn. Auth0872 respectively. Collected plant were washed, shade dried, powdered, sieved through an 85-mesh (BSS) sieve and stored in an airtight container at $25 \pm 5^{\circ} \mathrm{C}$ to prevent the growth of microorganisms. Plant powders prepared thus, were used for efficacy studies.

\section{Continuous hot extraction}

The various concentration of ethanolic extract of leaves of Datura metel was prepared by using distilled water. $20 \%, 40 \%, 60 \%$ were used.

\section{Head lice}

A colony of P.humanus capitis was collected by combing the hair of 20-25 infected children at the age group of 10-15. Head lice were reared in the glass vessels covered with nylon mesh containing tufts of hairs.

\section{Feeding of head lice}

To feed head lice with blood meals they were kept on the lower leg of the human beings and maintain there for 30 minutes. Microscopy examination of the mid- gut confirmed blood ingestion.

\section{Bio assay}

The hair tufts was impregnated with appropriate doses for the screening. Control hair tufts receiving the vehicle were also maintained, marketed sample were used as a standard. Batches of 20 adult P.humanus capitis given a human blood meal before the bioassay were placed on each vessel containing few strands of human hair and it was covered with the nylon mesh. Treated and control and standard were held at $37 \mathrm{oc}$ in darkness. Each concentration was maintained at triplicate and number of mortality was recorded for every 30 minutes. Death was defined as lack of movement of limbs and guts and failure to respond when the legs were stroked with forceps and the results were tabulated.

Since the isolated fraction were less quantity, if was not possible to carry out the experiment in triplicate. So the percentage mortality after 60 min and 90 minutes were tabulated.

\section{Method}

Disc diffusion method

\section{Organism used}

Malassezia furfur (MTCC:1374)

Preparation of the medium

$2 \mathrm{gm}$ of SDA medium and $1 \mathrm{gm}$ of Agar was dissolved in $50 \mathrm{ml}$ of distilled water heat to boiling to dissolve the medium completely, sterilize by autoclaving at $15 \mathrm{lbs}$ pressure $(121 \mathrm{oC}$ for $15 \mathrm{mts} \mathrm{pH}$ is adjusted to $(5.6$ $\pm 2 \mathrm{oC})$. The medium was poured into the sterile petridishes to get a thickness of $5-6 \mathrm{~mm}$. The medium was allowed to solidify and petridish was inverted and were dried at 37 oc just before inoculation.

Inoculum preparation

The peptone was added to the liquid SDM in the concentration of $5,10,15$ and $20 \mathrm{~g} / \mathrm{lr}$. Pure culture of M. furfur grown in liquid medium was inoculated and incubated at $30 \pm 2 \mathrm{oC}$ for 7 days.

Collection and maintenance of the culture

Pure culture of M.furfur (MTCC: 1374) was obtained from institute of Microbial type of culture collection, Chandigarh, India. The culture was maintained in SDA medium.

Antimycotic assay (Disc - diffusion method)

The broth culture of M.furfur was swabbed over the sabouraud dextrose agar by using stierile cotton buds. Sterile $5 \mathrm{~mm}$ diameter whatman No. 32 filter paper discs were dipped in plant extracts and clotrimazole (Standard drug10 $\mu \mathrm{g} / \mathrm{disc}$ ) and control DMSO disc were placed equidistantly $(3 \mathrm{~cm}$ apart) round the margin of the plates. Three replicates were maintained. The plates were incubated at $30 \pm 20 \mathrm{C}$ and zone inhibition was observed after 3 days. The results were tabulated here.

This research covers the works on invitro antilice and anti dandruff screening of Datura metee, in an attempt to rationalize its use as single drug of therapeutic importance with dual benefit.

\section{DISCUSSION}

Though all of the pediculicidal agents act efficiently against P.humanus capities, some of them are neuro toxic. Moreover, the continued use

Table 1: Anti lice activity of ethanolic extract and ethonolic extract with various carrier oils.

\begin{tabular}{|c|c|c|c|c|c|}
\hline S.No & Lice released & Text Drug & Conc. $\mathrm{g} / 10 \mathrm{mls}$ & $\begin{array}{c}\text { Mean } \pm \text { SEM \% mortality } \\
60 \mathrm{~min} \\
\end{array}$ & $\begin{array}{c}\text { Mean } \pm \text { SEM \% mortality } 90 \\
\text { min }\end{array}$ \\
\hline 1 & $\mathrm{~N}=20$ & & 2 & - & $3.3333 \pm 1.667$ \\
\hline 2 & $\mathrm{~N}=20$ & Aqueous paste & 4 & $13.3333 \pm 1.667$ & $23.3333 \pm 1.667$ \\
\hline 3 & $\mathrm{~N}=20$ & & 6 & $23.3333 \pm 1.667$ & $43.3333 \pm 1.667$ \\
\hline 4 & $\mathrm{~N}=20$ & & 2 & $3.3333 \pm 1.667$ & $16.666 \pm 1.667$ \\
\hline 5 & $\mathrm{~N}=20$ & EEDC & 4 & $23.3333 \pm 1.667$ & $45.000 \pm 2.887$ \\
\hline 6 & $\mathrm{~N}=20$ & & 6 & $61.6666 \pm 2.887$ & $98.333 \pm 1.667$ \\
\hline 7 & $\mathrm{~N}=20$ & & 2 & $23.3333 \pm 1.667$ & $47.61 \pm 1.002$ \\
\hline 8 & $\mathrm{~N}=20$ & EEDC + Coconut Oil & 4 & $41.6666 \pm 3.333$ & $65.32 \pm 2.112$ \\
\hline 9 & $\mathrm{~N}=20$ & & 6 & $98.3333 \pm 1.667$ & - \\
\hline 10 & $\mathrm{~N}=20$ & & 2 & $8.333 \pm 1.667$ & $18.333 \pm 1.667$ \\
\hline 11 & $\mathrm{~N}=20$ & EEDC + gingelly oil & 4 & $28.333 \pm 1.667$ & $48.333 \pm 1.667$ \\
\hline 12 & $\mathrm{~N}=20$ & & 6 & $68.3333 \pm 1.667$ & $98.333 \pm 1.667$ \\
\hline 13 & $\mathrm{~N}=20$ & & 2 & $3.3333 \pm 1.667$ & $21.666 \pm 1.667$ \\
\hline 14 & $\mathrm{~N}=20$ & EEDC + Castor oil & 4 & $23.3333 \pm 1.667$ & $53.333 \pm 1.667$ \\
\hline 15 & $\mathrm{~N}=20$ & & 6 & $65.24 \pm 1.667$ & $98.333 \pm 1.667$ \\
\hline 16 & $\mathrm{~N}=20$ & Standard marketed sample & $10 \mathrm{ml}$ & $98.666 \pm 0.5774$ & - \\
\hline
\end{tabular}


Table 2: Anti lice activity of isolated fractions.

\begin{tabular}{|c|c|c|c|c|}
\hline \multirow{2}{*}{ S.No. } & \multirow{2}{*}{$\begin{array}{c}\text { Fractions No (Concentration } \\
5 \%) \\
\end{array}$} & \multirow{2}{*}{ Number of lice released } & \multicolumn{2}{|c|}{$\%$ mortality } \\
\hline & & & 60 Minutes & 90 Minutes \\
\hline 1. & F-4 & 20 & 25 & 50 \\
\hline 2. & F-8 & 20 & 40 & 60 \\
\hline 3. & F-9 & 20 & 60 & 70 \\
\hline 4. & F-16 & 20 & 55 & 65 \\
\hline 5. & $\begin{array}{l}\text { Standard marketed sample } \\
\qquad(10 \mathrm{ml})\end{array}$ & 20 & 98 & - \\
\hline
\end{tabular}

Table 3: Antifungal activity of ethanolic extract of Datura metel against m.furfur.

\begin{tabular}{|c|c|c|c|}
\hline S.No. & Drug & Concentration & Zone of inhibition \\
\hline \multirow[t]{4}{*}{1.} & Ethanolic extract & $50 \mathrm{mg} / \mathrm{ml}$ & Nil \\
\hline & & $100 \mathrm{mg} / \mathrm{ml}$ & Nil \\
\hline & & $250 \mathrm{mg} / \mathrm{ml}$ & $6 \mathrm{~mm}$ \\
\hline & & $500 \mathrm{mg} / \mathrm{ml}$ & $9 \mathrm{~mm}$ \\
\hline 2. & Standard (clotrimazole) & $10 \mu \mathrm{g} / \mathrm{disc}$ & $15 \mathrm{~mm}$ \\
\hline 3. & Control DMSO & - & - \\
\hline
\end{tabular}

of these products induces resistance. Non toxic alternative options are hence needed for head lice treatments which prompted us this study invitro anti lice activities of and agueous paste, ethanolic extract and along with the fixed oil as carrier and isolated fractions of leaves of Datura metelwere studied. ${ }^{8}$ It was observed that after 90 minutes in the percentage mortality observed for the concentration $2,4,6 \mathrm{~g} / 10 \mathrm{ml}$ were $3.33 \pm 1.66723 .33 \pm 43.33 \pm 1.66,16.66 \pm 1.66,45 \pm 2.88,98.33 \pm 1.66$ for aqueous paste, EEDC respectively. For EEDC + Coconut oil mortality was significant in an 60 minutes which was $98.33 \pm 1.66$. All the readings are mean \pm SEM for triplicate values. ${ }^{9}$ From the above it is clear that the decrease in percentage of mortality is in the following order after 60 minutes. EEDC + coconut oil $>$ EEDC + gingelly oil $>$ EEDC + castor oil $>$ EEDC $>$ aqueous paste, at the concentration of $6 \mathrm{gms} / 10 \mathrm{ml}$ which is comparable to the standard. The ethanolic extract of leaves of Datura metelmixed in coconut oil as carrier possesses significant antilice activity. $(\mathrm{p}<0.05)$ Since the isolated fraction were in less quantity, it was not possible to carry out the experiment in triplicate. ${ }^{10}$ It was observed that the decrease in mortality in the biologically active isolated fractions where as follows at 5\% concentration. F-9 $>$ F-16>F-8>F-4 showed moderate activity and it can be assumed that no single fraction has shown significant mortality. So this study revealed that the combination of phytoconstituents present in the ethanolic extract of leaves of Datura metelposses combined anti lice activity than the isolated fractions. Previously it was reported that, the n-hexane and chloroform extracts of aerial part of Datura metelshowed antifungal activity against Aspergillus niger and Mucor species at $10 \mathrm{mg} / \mathrm{ml}$ concentration but the chloroform extract showed activity only at higher concentration. ${ }^{11}$ This study and the ethnomedical use prompted us to carry out the Antidandruff screening study. The antidandruff activity of ehanolic extract of Datura metelagainst Malassezia furfur was studied by disc diffusion method, in SDA medium the zone of inhibition was measured. It was observed that the zone of inhibition was moderate when compared to the standard drug (clotrimazole and Zone of inhibition was slightly concentration dependent \& not significant and having moderate inhibition. There was mild increase of inhibition by increasing concentration above $500 \mathrm{mg} /$ ml. ${ }^{12}$ The diameter of the zone of inhibition is influenced by a variety of factors such as diffusibility of the drug, disc concentration, the nature and composition of the medium, its thickness, presence of inhibitory or stimulatory substances, $\mathrm{pH}$ of the medium and the time of incubation. During incubation, the therapeutic agent diffuses out from the disc in all directions. ${ }^{13}$ Agents with lower molecular weights diffuse faster than agents with higher molecular weight might be a powerful inhibitor even though it may diffuse only a small zone of inhibition. Moreover, results obtained in vitro often differ from those obtained in vivo. Metabolic processes in the body of a living organism may inactivate or inhibit on antimicrobial compound. ${ }^{14}$ The anti lice activity against Pediculus humanus capitis (head lice) after 90 minutes, of the ethanolic extract of leaves of Datura metel in the concentration of $6 \mathrm{gm} / 10 \mathrm{ml}$ was studied. The mortality is concentration dependent. Application of aqueous paste not possesses significant antilice activity. Isolated fractions were tested showed that the activity may be synergistic by the presence of various Phytoconstituents. We were also able to demonstrate invitro moderate anti dandruff activity of the ethanolic extract leaves of Datura metel against M.furfur.

\section{CONCLUSION}

The current study provide scientific basis for the ethnomedical use of this plant as antilice application. It is concluded that it can be optimistic that the present work proved Datura metel of dual therapeutic advantage to be a potential phytochemical target in the design of a drug for the treatment of both lice and dandruff without causing any adverse influences on eyes, to alleviate the suffering the affected individuals. The above study require further investigation for the exact mechanism of action, to develop safe herbal formulation which can result in complementary to those existing pediculocidal agent, which are though acts efficiently they are neurotoxic and induced resistance. So, this provides nontoxic alternative options for both head lice and dandruff activities.

\section{REFERENCES}

1. Gupta AK, Chitme HR. Herbal Medicines for Health. Eastern Pharmacist 2000;440(41):28.

2. Hand SS. Herbal raw material and traditional remedies. Eastern Pharmasis 2000;447(38):23.

3. Harbone JB. Phytochemical Methods- A Guide to modern techniques of plant Analysis, $3^{\text {rd }}$ ed, Eswar Books, UK, 1998,36.

4. Handa SS, Kaulo MK. Supplement to Cultivation \& Utilization of Medicinal Plants. Jammu - Taw India, Regional Research Lab. 1996,39.

5. Kelkar SS. A text book of Parasitology" Ist ed, Popular Prakashan P(Ltd), New Delhi, 1990,165.

6. Lepeare $\mathrm{CH}$, Brochez $\mathrm{L}$, Haeghen $\mathrm{YV}$, Mabilde $\mathrm{C}$, Vander $\mathrm{S}$, et al. Method to remove force required to remove pediculus humanus capitis eggs from human hair. J Medical Entomology. 2005;42(1):89-93.

7. Ravichandran G, Bharadvaj VS, Kolhapure SA. Evaluation of the clinical efficacy and safety of Anti-dandruff shampoo in the treatment of dandruff. The Antiseptic. 2004;201(1):5-8.

8. Krishnamoorthy JR, Ranganathan S, Shankar SG, Ranjith MS. Dano: "A herbal solution for dandruff", African J Biotechnology. 2006;5(10):960-2. 
9. Vijayanthi G, Kulkarni C, Abraham A, Kolhapure SA. Evaluation of antidandruff activity and safety of polyherbal hair oil. The Antiseptic. 2004;101(9):368-78.

10. Fortie J, Nkengfuck AE, Peter MG, Heydenreich M, Fomunn ZT. Chemical constituents of the ethyl acetate extracts of the stem bark and fruits of $D$. cinerea and the roots of parkia bicolor. Bull Chemical Society Ethiopia. 2004;18(1):111-5.

11. Dennin TJ, Joseph TG, Mishra KP, Billore KV. Pharmacognostic study of the root of Dichrostachys cinerea (L) Wight \& Arn. Indian med Yoga Homeopath. 1979;14(2):80-8.
12. Zeichner BC. Baseline Susceptibility of a Laoratory Strain of Pediculus humanus humanus (Anoplura: Pediculidae), using a modified world health organization testing protocol. J Medical Entomol. 1999;36(6).

13. Yang YC, Lee SH, Lee WJ, Choi DH, Ahn YJ. Ovicidal and Adulticidal Effects of Eugenia caryophyllata Bud and leaf oil compounds on Pediculus capitis. J Agric Food Chem. 2003;51(17)

14. Vijayakumar R, Muthukumar C, Kumar T, Saravanamuthu R. Characterization of Malassezia furfur and its control by using plant extracts. J Dermatology. 2006;51(2):145-8.

\section{GRAPHICAL ABSTRACT}

TOTAL CHOLESTEROL

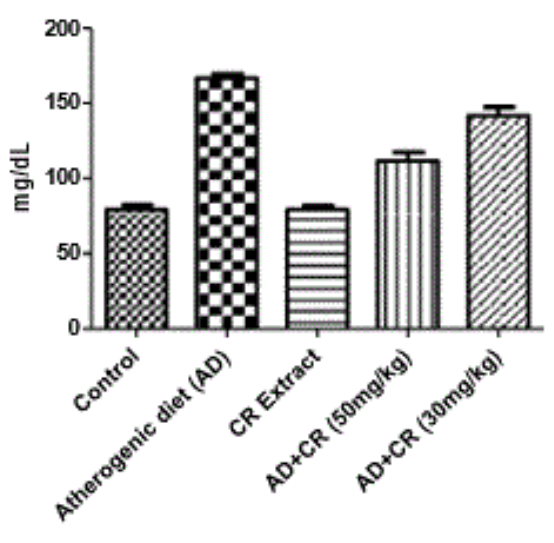

GLUCOSE

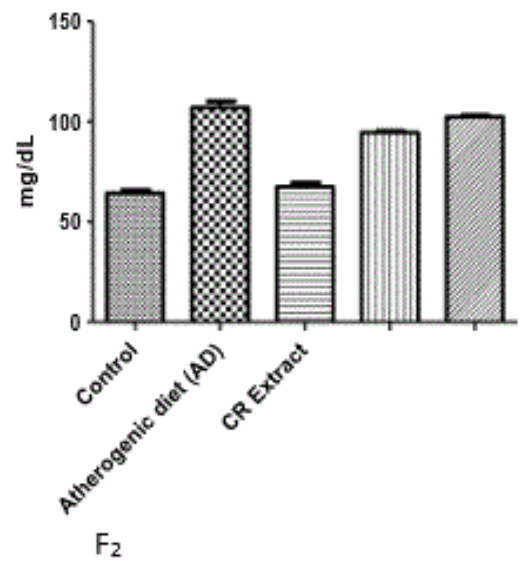

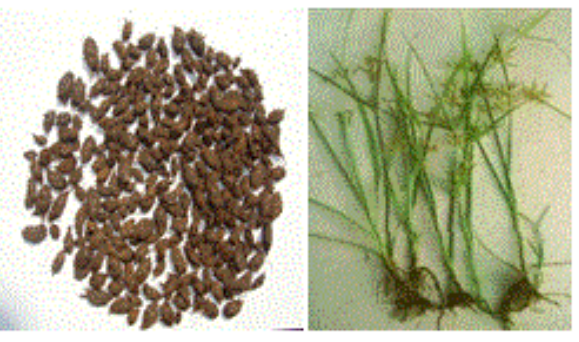

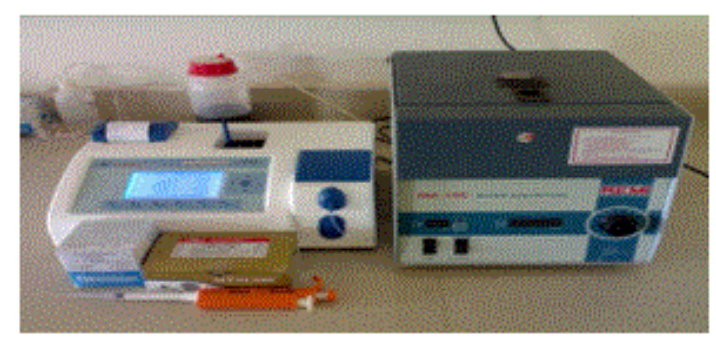

\section{ABOUT AUTHORS}

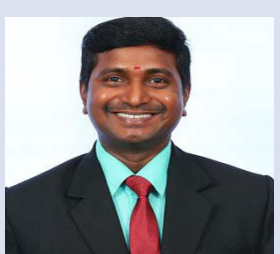

Dr.V. Sreedhar, who officiates as a Principal of Balaji College of Pharmacy, Ananthapuramu awarded Ph.D from SKU, Ananthapuramu. He is having 19 years of Teaching and Research experience in the area of Formulation Development and Novel Drug Delivery. He has Published/Presented Research/Review papers in various National \& International Journals. He is the member of Editorial board of reputed journals. He is recognized as an examiner and Research Supervisor for various reputed universities. He acted as a Resource Person, Chairperson, Adjudicator and Evaluator in various National Conferences. He has attended various workshops in Pharmacy. As an academician he has successfully established his present institution with $90-100 \%$ results. He is Registered Pharmacist. As community service, he conducted Blood Donation Camps, Medical Health Checkup Camps, Swatch Bharath Programs and Plantation of Medicinal plants. He conducted National Seminars, Workshops, Conferences and Training Programs to pharmacy students. 


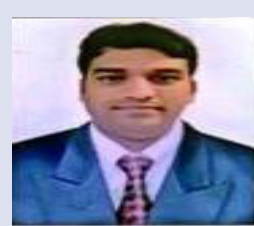

Dr. J. Mastanaiah, who officiates as a Professor \& Head, Dept. of Pharmacology, Balaji College of Pharmacy, Ananthapuramu awarded Ph.D from NIMS University, Jaipur. He is having 11 years of Teaching and Research experience in the area of Pharmacology and Toxicology. He has Published/Presented Research/ Review papers in various National \& International Journals. He is the member of Editorial board of reputed journals. He is recognized as an examiner for various reputed universities. He acted as Evaluator in various National Conferences. He has attended various workshops in Pharmacy. He is Registered Pharmacist. He conducted National Seminars, Workshops, Conferences and Training Programs to pharmacy students.

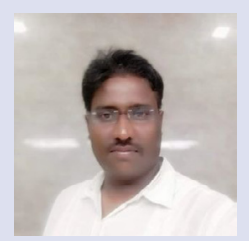

Mr.B. Chakrapani, who officiates as an Associate Professor, Dept. of Pharmacology, Balaji College of Pharmacy, Ananthapuramu registered Ph.D from Vel's University, Chennai. He is having 9 years of Teaching and Research experience in the area of Pharmacology and Toxicology. He has Published/ Presented Research/Review papers in various National \& International Journals. He is recognized as an examiner for various reputed universities. He acted as Evaluator in various National Conferences. He has attended various workshops in Pharmacy. He is Registered Pharmacist. He conducted National Seminars, Workshops, Conferences and Training Programs to pharmacy students.

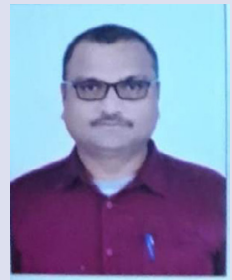

Dr. D. Venkatanarayna, who officiates as a Professor, Dept. of Pharmacognosy, Balaji College of Pharmacy, Ananthapuramu awarded Ph.D from JNTU, Ananthapuramu. He is having 10 years of Teaching and Research experience in the area of Pharmacognosy and Phytopharmaceuticals. He has Published/ Presented Research/Review papers in various National \& International Journals. He is the member of Editorial board of reputed journals. He is recognized as an examiner for various reputed universities. He acted as Evaluator in various National Conferences. He has attended various workshops in Pharmacy. He is Registered Pharmacist. He conducted National Seminars, Workshops, Conferences and Training Programs to pharmacy students.

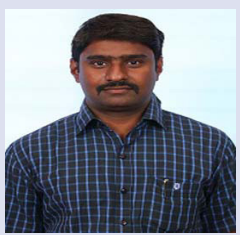

Mr. B. Nagendra babu, who officiates as a Professor, Dept. of Pharmacognosy, Balaji College of Pharmacy, Ananthapuramu. He is having 10 years of Teaching and Research experience in the area of Pharmacognosy and Phytopharmaceuticals. He has Published/Presented Research/Review papers in various National \& International Journals. He is the member of Editorial board of reputed journals. He is recognized as an examiner for various reputed universities. He acted as Evaluator in various National Conferences. He has attended various workshops in Pharmacy. He is Registered Pharmacist. He conducted National Seminars, Workshops, Conferences and Training Programs to pharmacy students.

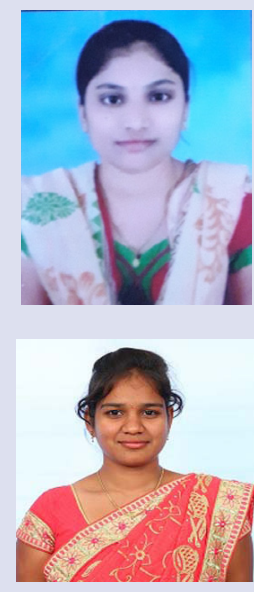

Mrs. M. Sushma, who officiates as an Assistant Professor, Dept. of Pharmacology, Balaji College of Pharmacy, Ananthapuramu. She is having 02 years of Teaching and Research experience in the area of Pharmacology and Toxicology. She has Published/Presented Research/Review papers in various National \& International Journals. She has attended various workshops in Pharmacy. She is Registered Pharmacist.

Ms. C. Ushasree, who officiates as an Assistant Professor, Dept. of Pharmacology, Balaji College of Pharmacy, Ananthapuramu. She is having 02 years of Teaching and Research experience in the area of Pharmacology and Toxicology. She has Published/Presented Research/Review papers in various National \& International Journals. She has attended various workshops in Pharmacy. She is Registered Pharmacist.

Mrs. N. Krishnasree, who officiates as an Assistant Professor, Dept. of Pharmacology, Balaji College of Pharmacy, Ananthapuramu. She is having years of Teaching and Research experience in the area of Pharmacology and Toxicology. She has Published/Presented Research/Review papers in various National \& International Journals. She has attended various workshops in Pharmacy. She is Registered Pharmacist.

Cite this article: Sreedhar V, Mastanaiah J, Chakrapani B, Narayana DV, Babu BN, et al. Pharmacological Screening of Anti Lice and Antidandruff Activity of Ethanolic Extract of Leaves of Datura metel. Pharmacogn J. 2020;12(6)Suppl:1653-7. 